Method Data Source Victorian Admitted Episodes Dataset (VAED) General case inclusion criteria:

Age 65 years and older

First (left-most) external cause code indicates a fall (W01-W19) AND Primary Diagnosis is injury or poisoning

Cases transferred from another acute care hospital and deaths in hospital were excluded

Analysis Rates were age-adjusted and trends were determined using a log-linear regression model of the rate data assuming a Poisson distribution of cases.

Results Over the decade 1998/1999 to 2007/2008:

falls increased by an estimated $22.5 \%$

hip fractures decreased by an estimated $23.4 \%$

all fractures showed a non-significant downward trend fractures excluding the hip increased significantly by $12 \%$ pelvic fractures increased significantly by $12 \%{ }^{*}$ open wounds $(57 \%)$, superficial injury (25\%), dislocations, sprains, strains (24\%) and intracranial injury (106\%) all increased significantly.

Discussion The observed decrease in the hip fracture is a welcome development, but caution should be exercised when interpreting/using this finding as it requires further investigation and confirmation. There is some confirmatory evidence from New South Wales, New Zealand and elsewhere where reports indicate that hip fracture hospitalisation rates for persons aged 65 years and over have stabilised, or decreased slightly in some age or gender groups, through the 1990s (Boufous et al, 2004; Fielden et al, 2001).

\title{
0706 DOWNWARD TREND IN HIP FRACTURE RATES IN PERSONS AGED 65 YEARS AND OLDER, VICTORIA, AUSTRALIA
}

E Cassell*, A Clapperton Correspondence: Monash University Accident Research Centre, Building 70, Accident Research Centre Monash University, Monash 3800, Australia

10.1136/ip.2010.029215.706

Aim Examine the trend in fall-related hip fracture hospital admission rates among Victorian seniors aged 65 years and older over the decade 1998/9 to 2007/2008. 